\title{
A MULTIPLE CRITERIA FRAMEWORK TO EVALUATE BANK BRANCH POTENTIAL ATTRACTIVENESS
}

\author{
Fernando A. F. FERREIRA ${ }^{1}{ }^{凶}$, Ronald W. SPAHR ${ }^{2}$, Sérgio P. SANTOS ${ }^{3}$ \\ and Paulo M. M. RODRIGUES 4
}

${ }^{1}$ School of Management and Technology, Polytechnic Institute of Santarém, Complexo Andaluz, Apartado 295, 2001-904 Santarém, Portugal and Fogelman College of Business and Economics, University of Memphis, Memphis, TN 38152-3120, USA

E-mail: fernando.ferreira@esg.ipsantarem.pt or fernando.ferreira@memphis.edu

${ }^{2}$ Department of Finance, Insurance and Real Estate, Fogelman College of Business and Economics, University of Memphis, Memphis, TN 38152-3120, USA

E-mail:rspahr@memphis.edu

${ }^{3}$ Faculty of Economics, University of Algarve, Campus de Gambelas, 8005-139 Faro, Portugal and CEFAGE, University of Évora, Portugal

E-mail: ssantos@ualg.pt

${ }^{4}$ Economics and Research Department, Banco de Portugal, Av. Almirante Reis 71, 1150-012 Lisboa, Portugal and Universidade Nova de Lisboa, Portugal and CEFAGE, University of Évora, Portugal

E-mail: pmrodrigues@bportugal.pt

Received 19 December 2011; accepted 21 February 2012

\begin{abstract}
Remarkable progress has occurred over the years in the performance evaluation of bank branches. Even though financial measures are usually considered the most important in assessing branch viability, we posit that insufficient attention has been given to other factors that affect the branches' potential profitability and attractiveness, such as: location features, trade area characteristics and facilities management. Based on the integrated use of cognitive maps and multiple criteria decision analysis, we propose a framework that adds value to the way that potential attractiveness criteria to assess bank branches are selected and to the way that the trade-offs among those criteria are obtained. This framework is the result of a process involving several directors from the five largest banks operating in Portugal, and follows a constructivist approach. Our findings suggest that the use of cognitive maps systematically identifies previously omitted criteria that may assess potential attractiveness. The use of multiple criteria techniques clarify and add transparency to the way trade-offs are dealt with. Advantages and disadvantages of the proposed framework are also discussed.
\end{abstract}

KEYWORDS: Bank branch; Location and facilities management; Potential attractiveness; Cognitive maps; MCDA

JEL Classification: C44, G21, L25, M10, R23

\section{INTRODUCTION}

It is widely accepted that the United States' subprime mortgage loan debacle precipitated the current precarious situation of the global markets. Many different scenarios exist regarding the causes of the subprime mortgage crisis and how it morphed into an interna- 
tional crisis, including the role that the United States government sponsored enterprises Fannie Mae and Freddie Mac played in escalating the crisis. Also many different perspectives, economic consequences and potential solutions to the crisis have emerged over the last few years (for a broader discussion, see Ferreira et al., 2011b; Kowalski and Shchmurove, 2011; Puri et al., 2011; Yeager, 2011; Beltratti and Stulz, 2012; Spahr and Sunderman, 2012; Wu, 2012; Xiao-yan et al., 2012). Regardless of the causes and potential solution for the economic crisis, there is a general consensus that the turmoil triggered a very sharp increase in competition in the banking sector. As defended by Wu (2012: 303), "financial institutions in particular have encountered more competitive challenges worldwide during the chain effects of the financial 'tsunami". Following this, few would contest that financial and banking institutions compete in a more complex and hostile environment in today's global economic climate, where it is absolutely necessary that each financial institution understands not only its mission and major objectives but also specifically identifies the strategies and tactics used to achieve them. Furthermore, globalization of financial markets, the recent financial crisis and evolving regulation are forcing substantial changes and reforms on financial institutions and, consequently, the ability for banks to mobilize, explore and evaluate tangible and/or intangible resources deserves increased interest from academics, regulators and bank management.

According to Carmeli (2004: 111-112), "the real source of competitive advantage is underlined by the organization's ability to consistently meet environmental changes (...) intangible, more than tangible, resources have potential for competitive advantage creation". Although the latest tendency to adopt multichannel banking strategies has been increasing, it seems evident that the traditional bank branch network still has a relevant role in the banking activ- ity. This idea seems to be supported by Serna (2005: 2), who argues: "bank branches are the primary place in which consumers have access to products for either building assets and/or obtaining credit".

Given that bank branches will continue to be a primary point of service, it seems evident that relative bank success will depend on the use of evaluation systems to measure bank branch performance and attractiveness. The fact that there are multiple intangible variables influencing branch attractiveness and profitability complicates the identification and development of evaluation systems. Many of the intangible variables are outside the banks' sphere of control, and this increases the interest (but also the difficulty) of developing potential attractiveness measurement frameworks (Davies, 1996). It is appropriate to clarify, however, that this study associates the term "potential attractiveness" to all external variables that fall outside (totally or partially) the banks' sphere of control, where these variables may create differentiation among existing branches by imposing strict constraints on their performance and influencing profitability. Therefore, variables such as quality of service, managers and personnel's activities, contacts in the community, courtesy and skills, will not be considered since these variables may be controlled by the banks' administration.

Although remarkable progress has taken place during the past two decades in the development of performance measurement frameworks (e.g. the balanced scorecard of Kaplan and Norton, 1992), it is recognized that there are still issues which deserve further research and further clarification. Two major intertwined categories of issues may be identified: the first refers to the way that (qualitative and/ or quantitative) evaluation criteria are selected and the second refers to the way that trade-offs among those criteria are made explicit. In this paper, we show how cognitive mapping and measuring attractiveness by a categorical based 
evaluation technique (MACBETH) (Bana e Costa and Vansnick, 1994; Bana e Costa et al., 2005; Bana e Costa et al., 2012) can be integrated and used to support the development of multidimensional performance evaluation systems that deal with bank branch potential attractiveness from a location and facilities management perspective. Considering that cognitive mapping and multiple criteria decision analysis (MCDA) have proven over the years to be very effective in handling these types of issues and in transparently incorporating multiple considerations into a decision making process, we believe that there is considerable scope to explore their applicability and relevance in this particular context. In this respect, it should be highlighted that, in this study, the branches' attractiveness is based on the bank manager's point of view and the performance evaluation exercise has an internal accountability purpose. Whilst the use of performance measurement for bank supervision and regulation is a very important and timely issue, this falls beyond the scope of our study and, therefore, is not discussed here.

This study aims to explore in depth part of a larger multiple criteria model for bank branch performance evaluation (Ferreira et al., 2011a), which was grounded on a case study that involved directors from the five largest banks that operate in the Portuguese banking system. These participants in the Ferreira et al. (2011a) study addressed, among other things, the potential attractiveness problem. Furthermore, by exploring the integrated use of cognitive mapping and MCDA in this particular context, we also aim to add to the operational research (OR) literature in banking, financial services and/or facilities management (Zopounidis, 1999; Zopounidis and Doumpos, 2003; Ferreira et al., 2011b). In particular, as stated by Zopounidis (1999: 412), "MCDA methods seem to have a promising future (...) because they offer a highly methodological and realistic framework to decision problems". We find no other documented evidence reporting the integrated use of these techniques to support the conception and desirable implementation of performance measurement systems for bank branch potential attractiveness.

To comprehend what has already been done on the analysis of potential attractiveness, we begin with a review of bank branch performance evaluation measures. We then present the way in which the methodologies have been used to develop the respective framework, and we further discuss the framework's strengths and weaknesses. We conclude by presenting some closing remarks and giving suggestions for further research.

\section{BRIEF REVIEW OF THE BANK BRANCH POTENTIAL ATTRACTIVENESS LITERATURE}

Since the late 1980s, worldwide reforms have been implemented for banking systems of all developed nations. Several factors have been behind these reforms, such as: globalization, standardized capital requirements, sector's liberalization, fusions and acquisitions, financial and technological innovation, crossselling, full-service branches, to name just a few. As a consequence of the organic growth of bank branches, they have become increasingly concentrated, not only geographically but also in terms of a limited number of (larger and consolidated) financial institutions, thus increasing competition (Hirtle, 2007; Ferreira et al., 2011a and 2011b). These circumstances have led banks to search for promising new branch locations and to compare relative branch performance based on a wide diversity of clients served and on the different competition conditions offered by each location. Therefore, banks have tried to establish and place into effect different decision support systems, "to allow for local conditions in planning new locations, evaluating performance and providing marketing support to their geographically 
separate units" (Boufounou, 1995: 389) (for a survey on covering problems in facility location, see also Farahani et al., 2012).

Despite this progress, it is important to bear in mind that the present economic and financial conditions place additional pressure on the branch networks evaluation ( $c f$. Puri et al., 2011). Following Zhao et al. (2004: 541), "although measures of financial performance are typically considered the most important in evaluating the viability of branches, there is evidence suggesting that a number of more general factors are important in assessing branch potential". From this point of view, it seems obvious that bank branch results are dependent not only on management performance but also on different "external" factors related to the branches' local conditions (for a broader discussion about location, see D'Amato, 2010).

Our assumption of "potential attractiveness measurement" is supported by Boufounou (1995: 391), who states: "in order for performance measurement to be sufficiently reliable, it has to explicitly capture the effects of "external" factors into branch results". According to the author, those external variables are mainly connected to location features, trade area characteristics, competitive situation features and internal branch characteristics. However, we posit that insufficient attention and improper treatment has been given to those factors, namely because they fall outside the banks' sphere of control.

Four different categories of performance evaluation methodologies have emerged according to Parkan and Wu (1999) and Ferreira et al. (2011a): (i) ratios and indices, that report simple analysis between two or more variables, and are known as traditional measures of performance evaluation; (ii) parametric or econometric approaches, that report statistical analysis based on known distributions and obey to certain parameters (e.g. linear regressions, correlation analysis, factorial analysis, among others); (iii) non parametric approaches or distribution-free tools, that do not obey any particular distribution, but cannot be extrapolated from the context of analysis (they depend on the available data, on the evaluated units and/or on the period of analysis) (e.g. benchmarking, data envelopment analysis (DEA), among many others); and (iv) integrated systems for performance evaluation, that combine complementary methods and are based on a learning and constructivist perspective (e.g. balanced scorecard (BSC)). A discussion of each of the four different categories characteristics and respective strengths and weaknesses falls beyond the scope of this paper. Still, according to $\mathrm{Wu}$ (2012: 303), "these approaches vary regarding their basic concepts, aims, advantages, and disadvantages (...)[and their appropriateness and use] depend on the situation and the type of organization"; and we are unaware of any existing literature using these methodological approaches that explicitly addresses bank branch potential attractiveness. However, there are some studies that have partially treated the bank branch potential attractiveness problem.

Avkiran (1995) offers an interdisciplinary and multivariate perspective for an integrated analysis of bank branch performance. The author's contribution is, therefore, relevant in the sense that he aims to minimize the gap between current branch performance and branch potential. His use of econometric techniques is based on variables that are controllable by bank management. Thus, his study is considerably different than ours, not only in methodological terms, but also because we believe that there are several other variables that fall outside the bank's sphere of control that may influence bank branch potential attractiveness.

Boufounou (1995) employs econometric models to produce a set of equations that predict the main dimensions of branch performance. He argues that external elements should be included in the decision making process, and regards volume of deposits as the 
major evaluation criterion of branch performance. He then establishes causal relationships between this measure of performance and the number of rentiers in the branch trade area, branch age, number of employees (associated to the branch's size) and presence of night deposit facilities (which represents an exterior attractiveness design feature, according to the author). Finally, he estimates branches' potential attractiveness by comparing each one of the branches' scores with the overall average.

Ittner et al. (1997) develop a branch quality index based on the integrated use of BSC and metrics, and applied their framework on a group of branches of the USA Western region. By performing several interviews with senior executives, the authors recognized difficulties (and possible omissions) in the way that evaluation criteria have been selected, disaggregated and explained. Despite the progress that has taken place in overcoming this problem (e.g. Kaplan and Norton, 2000; Suwignjo et al., 2000; Santos et al., 2002 and 2008), it is recognized that there are still issues which deserve further research and discussion. The same is reported as far as trade-off procedures among criteria is concerned.

Manandhar and Tang (2002) present a study that incorporates intangible aspects into a DEA framework. Their interpretation of potential attractiveness is different from ours, since they focused on internal service quality while we assume that potential attractiveness results from the influence of external variables that fall outside the banks' sphere of control. Their contribution is important since it highlights the multiple-dimension of intangible aspects. Manandhar and Tang (2002) also highlight the fact that, in the DEA approach, homogeneity among the decision units is assumed. Nevertheless, differences in environmental factors such as neighborhood population and branches' age can introduce heterogeneity. In this way, the interest of this study is also concerned with the discussion of including envi- ronmental (i.e. external) factors in the decision making evaluation process.

Paradi and Schaffnit (2004) offer a DEA application where two production models are developed. In one of those models, an environmental factor is introduced with the scope of capturing the level of economic growth in each one of the geographical areas under study. Although this study does not offer much to the potential attractiveness context, it is important in the sense that it tries to align bank managers' judgements with performance measures that support the strategic goals.

Zhao et al. (2004) explore the way in which geographical criteria and a more explicit spatial approach can be used to identify branches as candidates for closure and to provide decision makers with a more formal approach to branch bank strategy planning. The contribution of these authors seems to be extremely important in the context of the present paper, because despite the fact that financial performance is typically seen as the most important in evaluating branches' viability, they suggest that a number of more general factors should also be considered in assessing branch potential. Moreover, their study is partially based on multiple criteria decision making (MCDM) techniques, which corroborate some of our orientations (for a deeper discussion on MCDM/ MCDA, see Roy and Vanderpooten, 1997; Belton and Stewart, 2002).

In broad terms, these studies provide significant contributions to the field of bank branch potential attractiveness, namely, they identify, discuss and utilize several key evaluation criteria such as: demographic and population characteristics, customer behavior, physical location, accessibility, spatial competition, number of firms in the branches' areas, presence of competitors, average annual family income, etc. Other studies, with different purposes and/ or in different contexts, also offer important contributions for our bank branch evaluation study. For example, Frei and Harcker (1999) 
and Frei et al. (1999) explore the relation between retail banks' branch-based processes and financial performance; Hartman et al. (2001) make use of the DEA technique to deal, among other things, with the size of market potential; Davis and Albright (2004) propose a comparative study to determine if the use of a BSC, as a performance measurement system, may influence the financial performance of bank branches; Barros et al. (2007), based on a mixed logit approach, confirm country level characteristics (location and legal tradition) and firm-level features (bank ownership, balance sheet structure and size) as important determinants of bank performance; Bontis et al. (2007) found, among other things, that reputation partially mediates the relationship between customers' satisfaction and loyalty; Hirtle (2007) considers the bank overall strategy and studies the impact of network size on bank branch performance; Kauko (2007) suggests the use of pairwise comparison of attributes and the analytic hierarchy process (AHP) to rank location attributes; and Bergendahl and Lindblom (2008) highlight the need to consider the territory and neighborhood's developments where bank branches operate in.

Whilst important advances have been made, a review of the literature allows us to conclude that these approaches are not without their own weaknesses, namely the way that evaluation criteria are selected and the way trade-offs among them are calculated. In particular, Kauko (2010) states that "academic work on defining the relevant indicators is yet speculative, due to a shortage of standard definitions and relevant data". Following this, it is our believe that the integrated use of cognitive mapping and the MACBETH approach can inform and support the development of more effective performance systems by bringing new insights to the bank branch potential attractiveness context. In particular, cognitive maps help to reduce the rate of omitted criteria and promote a deeper understanding of the relationships among those criteria (Eden, 2004). On the other hand, by generating cardinal value functions capable of representing the decision makers' semantic preferences, MACBETH tends to facilitate the process of calculating trade-offs among criteria, while it adds simplicity and transparency into the process.

Another unique characteristic of our framework is that a branch's attractiveness is based on the banker's point of view (i.e. how attractive a bank branch is, for example, to the head office/bank manager) and not on the customers' assessment of potential attractiveness. Based on possible competitive and demographic changes, our framework is designed to support a bank in establishing or adjusting performance objectives for each of its branches, allowing them to periodically monitor their progress. Specifically, these objectives may include the scaling up of operations for those branches that present high performance levels but also the scaling down of operations for the poor performers. Branch monitoring should be seen as an attempt to early detect market trends. As stated by Akhigbe and McNulty (2011: 531), “(..) monitoring is value enhancing (...)" (for further discussion, see also Kaya and Kahraman, 2011). Furthermore, during periods of economic and financial turbulence as is currently being experienced by banking institutions, many banks are forced to close branches in an effort to cut costs and survive. Thus, the framework we propose, by identifying the poorest performers, may assist banks in selecting the branches to close.

\section{A MULTIPLE CRITERIA SYSTEM FOR POTENTIAL ATTRACTIVENESS EVALUATION}

As previously mentioned, we find no prior literature reporting the integrated use of cognitive mapping and the MACBETH approach applied to bank branch potential attractiveness. Thus, we discuss how these techniques 
may facilitate the process of selecting assessment criteria and calculating the trade-offs among those criteria.

Cognitive maps are important tools used for structuring and clarifying complex problems (cf. Ackermann and Eden, 2001; Cossette and Audet, 2003; Eden, 2004; Eden and Ackermann, 2004) mostly because of their interactivity, versatility and simplicity. Cognitive maps may be used to: (i) promote discussion among the decision makers involved in the decision aid process, (ii) reduce the omission rate of important criteria and (iii) lead to an increasing learning based on a deeper understanding of the causal relations among criteria. As for MACBETH, it is an interactive technique that supports the construction of numerical scales of intervals based on the decision makers' semantic judgements (for further details, see Bana e Costa and Vansnick, 1994; Belton and Stewart, 2002; Bana e Costa et al., 2005), which seems to be useful in dealing with tradeoff procedures in a bank branch potential attractiveness context, where most of the variables under discussion are qualitative. In fact, MACBETH is based on pairwise comparisons, which, according to Dyer and Forman (1992), are easy to make, discuss, justify and agree on (see also Kaya and Kahraman, 2011).

In exploring this line of research, several other methods can be applied (e.g. AHP, ANP, Conjoint Analysis, MAVF, MULTIMOORA, etc.). Earlier research carried out by Weber and Borcherding (1993) suggests that no superior elicitation method exists and that the methodology choice strongly depends on the decision context. Indeed, most of the studies carried out so far (e.g. Ananda and Herath, 2009) point to the fact that each method has strengths and weaknesses making it very difficult to prove that one methodology is superior to others in supporting the decision making process. This remark, together with the fact that the MACBETH technique has been recognized in the literature for facilitating trade-off calcula- tions among evaluation criteria, while adding simplicity and transparency into the decision process (cf. Belton and Stewart, 2002; Bana e Costa et al., 2005), and that this study extends previous work of Ferreira et al. (2011a), who have succeeded in the integration of cognitive maps and MACBETH in the particular context of bank branch performance evaluation, are the main reasons why these methods have been used in this study.

In the following sections, the way that the decision process was carried out is presented, which, according to the MCDA literature, was organized in three main phases: (1) the structuring phase, which is concerned with the application of cognitive maps as a tool to identify the key performance areas and indicators to assess bank branch potential attractiveness; (2) the evaluation phase, which is focused on the application of the MACBETH approach to make the relative importance of each performance area and indicator explicit; and (3) the recommendations phase of the study, which explored the integrated use of cognitive maps and MACBETH as means of adding value to existing practices regarding bank branch potential attractiveness evaluation. Advantages and shortfalls of the process are also discussed.

\subsection{The structuring phase}

The problem's structuring phase was developed in several work sessions over a two-week period. During this time, several issues were addressed, including: selection of decision makers and actors involved, "trigger question" definition, cognitive and strategic maps design, criteria definition and performance evaluation tree design, among others.

\subsubsection{Decision makers and actors involved}

Selection of decision makers is an important step in the structuring process of a complex problem because it will allow the facilitator (i.e. scientist, researcher or group of re- 
searchers) to define a panel of experts capable of assisting in the design and implementation of the performance evaluation system. For our study, two main problems were observed when deciding on the dimension of the panel of experts (or decision makers): (i) difficulties in getting the entire team together at the same time and in the same place; and (ii) limited availability of the top directors to participate in the group sessions. Given these constraints, we composed an initial panel of six members, most of whom are responsible for bank branch coordination. Regardless of the reasons of convenience, we were able to form a panel from the five largest banks that are operating in the Portuguese banking system. This allowed us to collect, confront and manage different strategic opinions and orientations for a large portion of the Portuguese banking system. In addition, a psychologist (responsible for assisting the facilitator/s in conducting the sessions) and a communication technician (responsible for registering the results achieved in each session) also participated in the work meetings.

\subsubsection{Problem definition}

As previously discussed, our decision framework aims at integrating both cognitive maps and the MACBETH approach in order to add value and increase effectiveness for each bank's branch potential attractiveness evaluation. Again, we emphasize that our concept of "potential attractiveness" includes all variables that fall outside (totally or partially) the banks' sphere of control but create differentiation among existing bank branches. Those variables do this by imposing strict constraints on their performances and, consequently, influencing their profitability. Therefore, the analysis of the problem consists of conceiving a model through the identification of multiple evaluation criteria and their interrelations, which are considered important in: (i) assessing bank branches' potential attractiveness; (ii) allowing comparisons among those branches under analysis and (iii) (if possible) providing improvement suggestions. Although rankings are presented, they are not the major aim of the proposed framework.

\subsubsection{Individual cognitive maps}

Following the strategic options development and analysis (SODA I) approach (Eden and Ackermann, 2001a and 2001b), the structuring process began with individual work sessions. At the beginning of each session, basic concepts related to the structuring and cognitive processes were carefully explained to the decision makers. Thorough explanations of our interpretation of "potential attractiveness" were also accompanied by a detailed discussion with the decision makers to avoid misunderstandings between them and the research team.

In order to begin the operational phase of the process and to promote discussion among the actors involved, a "trigger question" was presented: "From a bank's standpoint, and based on your values and experience, what are the main characteristics of an attractive bank branch?" (Again, decision makers were asked to reply according to the definition of the concept of "potential attractiveness" previously presented). For practicality, we used a table $(130 \mathrm{~cm} \mathrm{x} 80 \mathrm{~cm})$ especially designed for the study and applied the "post-its technique" (cf. Ackermann and Eden, 2001). That technique consists of writing what is considered, by the decision makers, as a relevant criterion on a post-it. This process is repeated until the decision makers recognize that there are no more criteria to be revealed. At this stage, the post-its are organized on the table by areas of concern with additional discussion regarding their significance.

\subsubsection{Linkages between criteria}

Based on earlier discussion regarding the areas of concern and respective clusters of criteria (represented by post-its), an internal 
analysis of each cluster's homogeneity and how it is differentiated from other clusters occurred. This analysis aimed to identify and better understand the relationships among identified criteria. Once this interactive process between decision maker and facilitator was concluded, the communication technician registered all links (as arrows) in each one of the individual cognitive maps and, at the end of each session, each decision maker was given the opportunity to reflect, reshape and/or restart the entire process (for further details, $c f$. Ackermann and Eden, 2001).

\subsubsection{The strategic map}

The preliminary version of the collective map (or "aggregated map") was proposed by the research team and it was based on the analysis of the previously formulated six individual maps. Aggregating all concepts developed during the previous individual work sessions was a very difficult and challenging task, not only because some criteria were often associated with different lines of thinking for dif- ferent individual decision makers, but also because similar terms and definitions were given to different criteria. It is important to clarify that this procedural step is often more of an art than a science and strongly depends on the facilitator/s' skills ( $c f$. Cossette and Audet, 2003). Despite the difficulties of aggregating all concepts developed by individual decision makers in the previous step, a preliminary version of the aggregated map was presented to the collective panel of decision makers, during a group workshop. The map representing the aggregation of all concepts was presented to panel members to promote discussion and to serve as a negotiation tool to reach a compromise solution for the problem. Following SODA I guidelines, the process was conducted in an interactive form and, despite the difficulties in achieving convergence in some situations, it only concluded with the decision makers' agreement on the form and content of the final map (also known as "congregated map" or "strategic map"). A small part of the strategic map is presented in Figure 1.

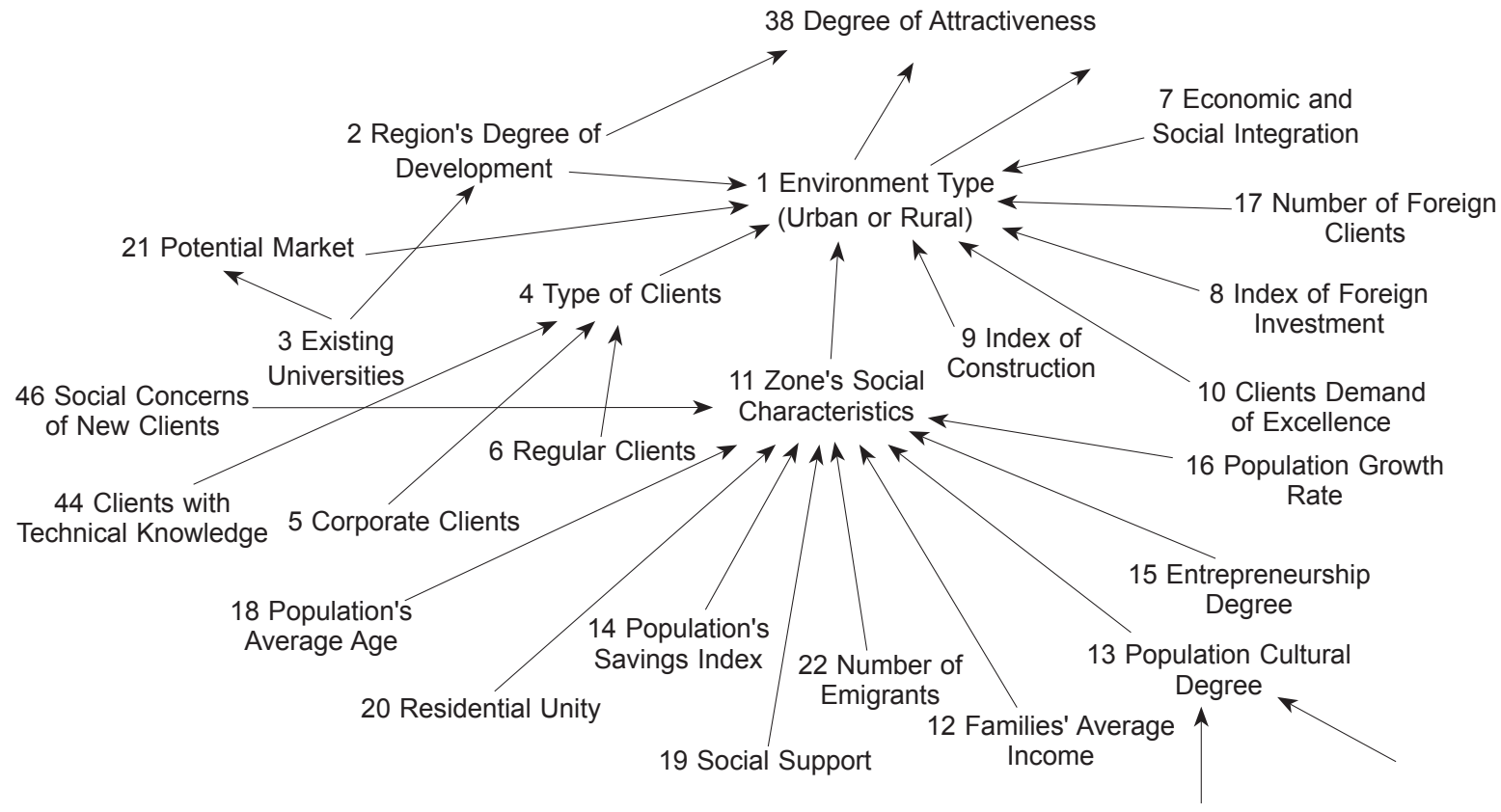

Figure 1. Part of the strategic map 
Due to the considerable size of the original strategic map, Figure 1 merely illustrates the criteria directly related to bank branch potential attractiveness. In should be recalled, however, that the map's final form was discussed with the group of experts, and represents the result of the negotiation and agreement reached by them. As can be easily deduced, the final version of the map includes several other evaluation criteria and shows how the potential attractiveness of the branches contributes to customers' satisfaction and, ultimately, to the profitability of the bank. Importantly, however, this conception relies on several factors, such as: session duration, facilitator skills, people involved, circumstances undertaken, etc. This means that the final version of the map could have been different in terms of form and/or content, had the context or the actors involved been different or had the sessions lasted longer. On this basis, and in spite of its subjectivity, the congregated map should be interpreted as a tool to provide consolidated information on decision issues based on perceptions of a certain group of decision makers. Thus, the use of cognitive mapping has proved very valuable to structure and improve understanding regarding the bank branch potential attractiveness issue. We should bear in mind that our work is process-oriented with adjustment possibilities.

\subsubsection{Criteria, descriptors and impact levels}

From the discussion with and among decision makers during a group session, it was possible to identify some critical bank branch potential attractiveness concepts, such as: location, environment and strategic dimension. Thus, based on the agreed upon collective map and following Keeney's (1992) methodological guidelines, it was possible to identify key performance indicators (i.e. evaluation criteria or points of view, represented by $\mathrm{CRT}_{\mathrm{n}}$ ) to assess bank branch potential attractiveness.
The process allowed the group to construct a tree of criteria, which has proven to be extremely important in the structuring process of our framework. This result was obtained not only because the process improved the problem's clarification but also because it allowed the actors to have a better understanding of the relationships among identified criteria. Again, it should be clarified that this structuring procedure is subjective, not a smooth transition, and depends strongly on the facilitator/s' skills. However, based on the high volume of information discussed and presented, the structuring task demonstrated that the construction of a tree of evaluation criteria becomes easier when based on a strategic map. Finally, with the support of the M-MACBETH software, a preliminary version of the tree was presented to the decision makers for discussion. Following the same constructivist approach adopted during the conception of the strategic map, the decision makers were strongly encouraged to discuss the tree and the meaning of each evaluation criterion. Decision makers were also allowed to introduce changes based on their collective perceptions, and the tree's proprieties were tested (cf. Ferreira et al., 2011a). Figure 2 illustrates the tree's final structure, which represents the decision makers' interpretation of the problem. Evaluation criteria are marked in bold.

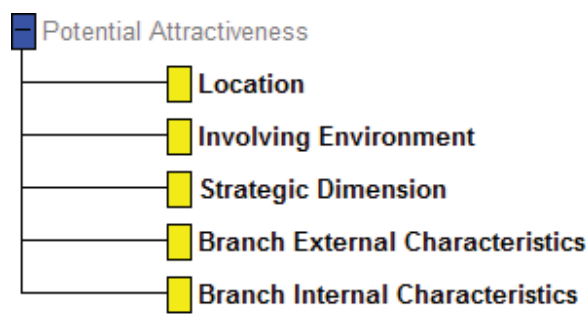

Figure 2. Tree of criteria

In practical terms, and according to the decision makers, $\mathrm{CRT}_{1}$ (Location) is designed to assess a bank branch's potential attractiveness based on its location. Location will be considered good or bad depending on variables such 
as: degree of isolation, accessibilities and possibility to implement business protocols; $\mathrm{CRT}_{2}$ (Involving Environment) is defined to reflect the environmental characteristics of the area where the branches are located. It seeks to introduce variables into the evaluation process such as construction index, foreign investment index and market potential; $\mathrm{CRT}_{3}$ (Strategic Dimension) is defined in order to introduce strategic concerns into the model. Variables such as the bank's prestige and the branch's antiquity (associated to tradition and/or potential growth) are introduced in the evaluation model by this criterion; $\mathrm{CRT}_{4}$ (Branch External Characteristics) addresses issues related to the branches' external layout. Although the external layout may not be a strong reason for a customer to begin or cease his/her relationship with the bank, it undeniably increases, based on the decision makers' opinion, the possibility of attracting new potential customers. Finally, $\mathrm{CRT}_{5}$ (Branch Internal Characteristics) concerns the branches' internal layout and highlights the importance of the branches' interior and physical infrastructures to increase (or not) the branches' potential attractiveness.

The two last criteria, according to the decision makers, are rarely taken into account in a bank branch potential attractiveness evaluation process. However, the use of cognitive mapping allowed their identification. Once the tree of criteria was discussed and accepted, the next step consisted of eliciting from the decision makers the construction of descriptors and respective impact levels for the criteria. Once again, based on the direct involvement of the decision makers, the structuring procedure allowed them not only to establish the proper basis of their value judgements but also to clarify how each branch's characteristics are assessed. For example, criterion $\mathrm{CRT}_{1}$ (i.e. Location) becomes operational by applying a descriptor, composed of eight ordered reference levels ( $L_{i}$ with $\left.i=1,2, \ldots, 8\right)$, that assesses the degree of isolation of a certain bank branch, while it balances several aspects, such as: accessibilities and proximity to economic agents (Table 1).

Table 1. Impact levels of the descriptor of the $\mathrm{CRT}_{1}$ (Location)

\begin{tabular}{|c|c|c|}
\hline Impact levels & Reference levels & Description \\
\hline $\mathrm{L}_{1}$ & & $\begin{array}{l}\text { Close to economic agents; Good accessibilities (i.e. parking and public } \\
\text { transportation); Good possibilities to implement business protocols. }\end{array}$ \\
\hline $\mathrm{L}_{2}$ & Good & $\begin{array}{l}\text { Close to economic agents; Good accessibilities (i.e. parking and public } \\
\text { transportation); Lack of possibilities to implement business protocols. }\end{array}$ \\
\hline $\mathrm{L}_{3}$ & Neutral & $\begin{array}{l}\text { Close to economic agents; Poor accessibilities (i.e. parking and public } \\
\text { transportation); Good possibilities to implement business protocols. }\end{array}$ \\
\hline $\mathrm{L}_{4}$ & & $\begin{array}{l}\text { Close to economic agents; Poor accessibilities (i.e. parking and public } \\
\text { transportation); Lack of possibilities to implement business protocols. }\end{array}$ \\
\hline $\mathrm{L}_{5}$ & & $\begin{array}{l}\text { Far from economic agents; Good accessibilities (i.e. parking and public } \\
\text { transportation); Good possibilities to implement business protocols. }\end{array}$ \\
\hline $\mathrm{L}_{6}$ & & $\begin{array}{l}\text { Far from economic agents; Good accessibilities (i.e. parking and public } \\
\text { transportation); Lack of possibilities to implement business protocols. }\end{array}$ \\
\hline $\mathrm{L}_{7}$ & & $\begin{array}{l}\text { Far from economic agents; Poor accessibilities (i.e. parking and public } \\
\text { transportation); Good possibilities to implement business protocols. }\end{array}$ \\
\hline $\mathrm{L}_{8}$ & & $\begin{array}{l}\text { Far from economic agents; Poor accessibilities (i.e. parking and public } \\
\text { transportation); Lack of possibilities to implement business protocols. }\end{array}$ \\
\hline
\end{tabular}


In line with the decision makers' interpretation of this descriptor, the lower the degree of isolation the higher the branch's partial score. Obviously, an upper and a lower impact levels, as well as a good and a neutral levels, had to be considered for each criterion. This procedure allowed sorting the impact levels in order to obtain value functions in each evaluation criterion. Note that the evaluation phase only begins after a complete definition of all impact levels in each criterion considered.

\subsection{The evaluation phase}

The evaluation phase was conducted mainly during a group work session to obtain the trade-offs among impact levels and among the model's evaluation criteria. As described below (section 3.2.3), this group work session also consisted of testing the performance of four bank branches and in the analysis and discussion of the results.

\subsubsection{Value judgements and local preferences}

To analyze local preference scales for the evaluation criteria and to obtain a cardinal value function for each of the descriptors, it was necessary to construct value judgement matrices. To assist in filling in the matrices, the MACBETH approach was applied based on predefined categories of semantic differences of attractiveness: $C_{0}-$ null, $C_{1}-$ very weak, $\mathrm{C}_{2}-$ weak, $C_{3}-$ moderate, $C_{4}-$ strong, $C_{5}-$ very strong and $C_{6}$-extreme. As reported in the literature (e.g. Bana e Costa and Vansnick, 1999), the approach was initially inspired on the mathematical principles of Doignon and based on numerical representations of semiorders for multiple thresholds. In fact, as discussed by Bana e Costa and Vansnick (1994), in an ordered structure of $m$ binary relations $\left[P^{(1)}, P^{(2)}, P^{(k)}, \ldots, P^{(m)}\right]$ (where $P^{(k)}$ stands for a preference that is stronger the greater the $k$ ), the numerical codification of preferences becomes possible. In practice, being $X=\{a, b, \ldots, n\}$ a finite set of $n$ actions, the MACBETH technical procedure consists in the association of each action of $X$ to a value $x$ (resulting from a value function $v():. X \rightarrow R)$ such that differences as $v(a)-v(b)$ (with $a P b$ (i.e. $a$ strictly more attractive than $b)$ ), are as compatible as possible with the decision makers' judgements. In this way, according to Bana e Costa and Vansnick (1994), for all pairs of actions $(a, b)$ allocated to a certain qualitative category $C$, the differences $v(a)-v(b)$ will belong to the same interval, without overlaps. More specifically, if $a$ is considered more attractive than $b$ and the difference between both actions is extreme, then ( $a$, $b) \in C_{6}$. Whereas two contiguous ranges correspond to two consecutive qualitative categories of difference of attractiveness, the technical procedure consists in associating asymmetric partitions of the ray of positive real numbers to partition classes of ordered pairs $(a, b)$ (with $a P b$ ) (see Bana e Costa et al., 2008). For this purpose, intervals between categories of consecutive differences of attractiveness are introduced based on a value function $v$ and function thresholds $s_{k}$ as presented in (1).

$$
a P^{(k)} b: \quad s_{k}<v(a)-v(b)<s_{k+1}
$$

Conceptually, being the thresholds $s_{k}$ positive real constants, the definition of intervals between semantic categories of differences of attractiveness becomes easier and, according to Bana e Costa et al. (2005), "the basic idea underlying the initial development of MACBETH was that limits of these intervals should not be arbitrarily fixed a priori, but determined simultaneously with numerical value scores for the elements of X'. As such, based on value preferences, the technical procedure consists in allocating the difference of attractiveness between each pair of actions $(a, b) \in X$ to one of the previously mentioned categories. Formulations (2) and (3) are also analyzed for consistency purposes (Junior, 2008).

$$
\forall a, b \in X: v(a)>v(b) \Leftrightarrow a P b
$$




$$
\begin{aligned}
& \forall k, k^{*} \in\{1,2,3,4,5,6\}, \forall a, b, c, d \in X \text { with }(a, b) \in C_{k} \\
& \text { and }(c, d) \in C_{k^{*}}: k \geq k^{*}+1 \Rightarrow v(a)-v(b) \geq v(c)-v(d)
\end{aligned}
$$

More specifically, formulation (2) presents the logical assumption that if action $a$ is strictly more attractive than action $b$ (i.e. $a P b$ ), then it is possible to associate numbers to these actions, such that $v(a)>v(b)$ (i.e. the value of action $a$ should be greater than the value of action $b$ ). Similarly, if no cognitive difference between actions is felt and, thus, action $a$ is as attractive as action $b($ i.e. $a I b)$, then $v(a)=v(b)$, and the pair $(a, b) \in C_{0}$. Based on the different semantic categories $C_{k}$ presented herein, formulation (3) states "that all of the differences allocated to one semantic preference difference category are strictly larger than those allocated to a lower category" (Bana e Costa et al., 2008: 28). Following this, and once analyzed the consistency of the experts' value judgements, a linear program that minimizes $v(n)$ is then applied according to (4) (Junior, 2008) in order to generate an initial scale, which should be presented for discussion among decision makers.

At this stage, it should be clarified that $n$ is the most attractive (or at least as attractive as the others) element of $X$ (i.e. $n(P \cup I) a, b, c, \ldots)$, and its value minimization takes place to guarantee the minimal length of the initial scale. On the other hand, $a^{-}$is the less attractive (or at least as attractive as the others) element of $X$ (i.e. $a, b, c, \ldots(P \cup I) a^{-}$), and its value should be anchored to the "zero" of the scale (for further technical details, see Bana e Costa et al., 2008). Based on formulation (4), Figure 3 exemplifies the technical procedures used to achieve the $\mathrm{CRT}_{1}$ value function. Nevertheless, it seems opportune to bear in mind that the process was repeatedly executed until each descriptor's local preference scale was defined.

It is also important to highlight the usefulness of the M-MACBETH software in resolving inconsistencies, since it offers opportunities for decision makers to reconsider their value judgements. Inconsistencies were promptly identified and addressed based on further discussion and/ or value judgement reconsideration. Decision makers were given the opportunity to express their values using semantic judgements, which may be a more natural form of value projection (cf. Bana e Costa and Chagas, 2004).

\section{$\operatorname{Minv}(n)$}

$$
\begin{aligned}
S . T . & : \forall a, b \in X: a P b \Rightarrow v(a) \geq v(b)+1 \\
& \forall a, b \in X: a I b \Rightarrow v(a)=v(b) \\
& \forall(a, b),(c, d) \in P \text {, if the difference of attractiveness between }
\end{aligned}
$$

$a$ and $b$ is bigger than between $c$ and $d$, then:

$$
v(a)-v(b) \geq v(c)-v(d)+1+\delta(a, b, c, d)
$$

$v\left(a^{-}\right)=0$

where:

$n$ is an element of $X$ so that $\forall a, b, c, \ldots \in X: n(P \cup I) a, b, c, \ldots$

$a^{-}$is an element of $X$ so that $\forall a, b, c, \ldots \in X: a, b, c, \ldots(P \cup I) a^{-}$

$\delta(a, b, c, d)$ is the minimal number of categories of difference of attractiveness between the difference of attractiveness between $a$ and $b$ and the difference of attractiveness between $c$ and $d$. 


\begin{tabular}{|c|c|c|c|c|c|c|c|c|c|}
\hline \multicolumn{9}{|c|}{ yㅡㄹ Location } & \multirow{2}{*}{$\begin{array}{c}\mathbf{X} \\
\begin{array}{c}\text { Current } \\
\text { scale }\end{array} \\
\end{array}$} \\
\hline 圆 & L1 & $\mathrm{L} 2$ & L3 & L4 & L5 & L6 & L7 & L8 & \\
\hline L1 & no & weak & moderate & moderate & strong & v. strong & v. strong & extreme & 200 \\
\hline $\mathrm{L} 2$ & & no & weak & moderate & strong & strong & v. strong & v. strong & 100 \\
\hline $\mathrm{L} 3$ & & & no & weak & mod-strg & strong & strong & v. strong & 0 \\
\hline L4 & & & & no & moderate & strong & strong & strong & -100 \\
\hline L5 & & & & & no & weak & moderate & strong & -300 \\
\hline L6 & & & & & & no & weak & moderate & -450 \\
\hline L7 & & & & & & & no & weak & -550 \\
\hline L8 & & & & & & & & no & -650 \\
\hline \multicolumn{10}{|c|}{ Consistent judgements } \\
\hline $\begin{array}{l}\text { 国 } \\
0 \times 1\end{array}$ & & 81 & 国将 & 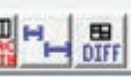 & 影 & & & & \\
\hline
\end{tabular}

\begin{tabular}{|r|r|r|r|}
\hline \multicolumn{2}{|c|}{ Location } & \multicolumn{1}{|c|}{} \\
\hline & $\begin{array}{c}\text { Current } \\
\text { scale }\end{array}$ & $\begin{array}{c}\text { MACBETH } \\
\text { anchored }\end{array}$ & $\begin{array}{c}\text { MACBETH } \\
\text { basic }\end{array}$ \\
\hline L1 & 200 & 200,00 & 17,00 \\
\hline L2 & 100 & 100,00 & 15,00 \\
\hline L3 & 0 & 0,00 & 13,00 \\
\hline L4 & -100 & $-100,00$ & 11,00 \\
\hline L5 & -300 & $-300,00$ & 7,00 \\
\hline L6 & -450 & $-450,00$ & 4,00 \\
\hline L7 & -550 & $-550,00$ & 2,00 \\
\hline L8 & -650 & $-650,00$ & 0,00 \\
\hline
\end{tabular}

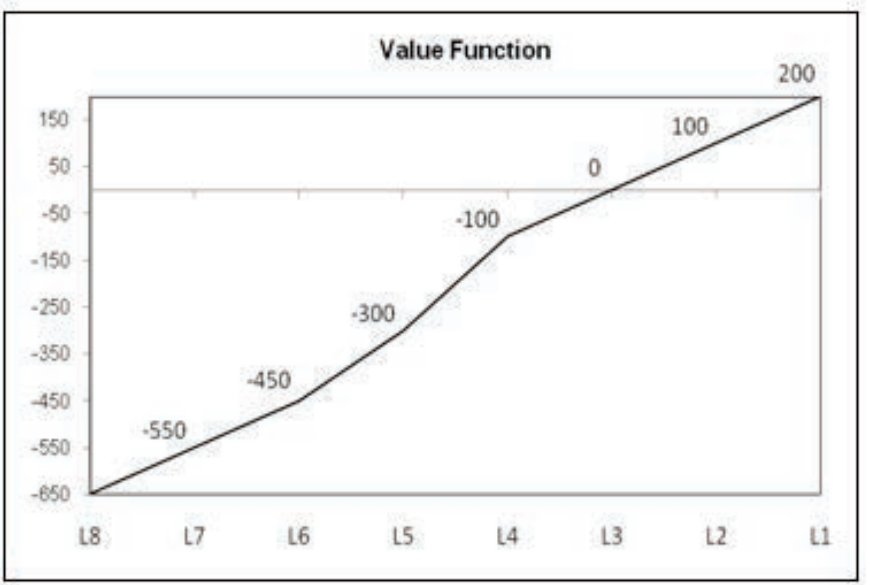

Figure 3. Value judgements, proposed scales and value function of the $\mathrm{CRT}_{1}$

At this stage, mutual preferential independence tests were also conducted, in order to guarantee preferential independence among criteria (for further details on this procedure see Bana e Costa and Chagas, 2004; Bana e Costa et al., 2005). Once cardinal value scales were obtained (i.e. local scales that allow bank branch partial assessment), the next step was to calculate the trade-offs among criteria (also known as weights or substitution rates). Those calculi were a pre-requisite to get an overall assessment of the bank branches.

\subsubsection{The trade-off procedures}

During this stage of the decision making process, decision makers were first asked to rank those criteria in terms of their overall attractiveness in order to obtain the trade-offs among criteria. This step used a matrix of comparisons to cognitively compare an alternative $a_{0}$ (composed of the worst impact levels) to an alternative $a_{n}$ (composed of the best impact levels) (for further details, see Bana e Costa and Chagas, 2004). Decision makers were then invited to express semantic values regarding the 
difference of attractiveness among the ordered criteria. The technical procedure was the same as the procedure used for the local scales calculi (cf. Figure 3) and, therefore, a MACBETH scale and respective trade-offs were proposed for discussion with and among decision makers (Figure 4).

Based on the trade-off values discussed and approved, the construction of an additive value model as presented in (5) (Bana e Costa et al., 2008), and the respective assessment of bank branches' partial and overall potential attractiveness, became possible.
As can be deduced, this additive model allows for the aggregation of the partial scores $v_{i}(a)$ and the calculation of the overall score $V(a)$, which represents a holistic measure of potential attractiveness for each bank branch under analysis. Also according to (5), it should be noted that $v_{i}\left(\right.$ good $\left._{i}\right)$ and $v_{i}\left(\right.$ neutral $\left._{i}\right)$ represent the partial scores of two specific performance levels (good and neutral, respectively), that have been defined for each descriptor to facilitate cognitive comparisons.

$$
V(a)=\sum_{i=1}^{n} x_{i} v_{i}(a) \text { with } \sum_{i=1}^{n} x_{i}=1 \text { and } x_{i}>0 \text { and }\left\{\begin{array}{l}
v_{i}\left(\operatorname{good}_{i}\right)=100 \\
v_{i}\left(\text { neutral }_{i}\right)=0
\end{array}\right.
$$

\begin{tabular}{|c|c|c|c|c|c|c|c|}
\hline \multicolumn{7}{|c|}{ (4), Weighting (Overall) } & $x$ \\
\hline 周 & [CRT1] & [CRT3] & [CRT2] & [CRT5] & [CRT4] & [ all lower ] & $\begin{array}{c}\text { Current } \\
\text { scale }\end{array}$ \\
\hline [CRT1] & no & moderate & strong & $\mathrm{v}$. strong & v. strong & exdreme & 35.71 \\
\hline [CRT3] & & no & weak & moderate & strong & v. strong & 23.81 \\
\hline [CRT2] & & & no & weak & moderate & strong & 19.04 \\
\hline [CRT5] & & & & no & moderate & strong & 14.29 \\
\hline [CRT4] & & & & & no & moderate & 7.15 \\
\hline [ al lower] & & & & & & no & 0.00 \\
\hline \multicolumn{8}{|c|}{ Consistent judgements } \\
\hline 需? & & + & $\mathrm{mon}$ & 界 & 直事 & & \\
\hline
\end{tabular}

$\mid$\begin{tabular}{|r|r|r|r|}
\hline & $\begin{array}{c}\text { Current } \\
\text { scale }\end{array}$ & $\begin{array}{c}\text { MACBETH } \\
\text { anchored }\end{array}$ & $\begin{array}{c}\text { MACBETH } \\
\text { basic }\end{array}$ \\
\hline [CRT1] & 35.71 & 35.71 & 15.00 \\
\hline [CRT3] & 23.81 & 23.81 & 10.00 \\
\hline [CRT2] & 19.04 & 19.04 & 8.00 \\
\hline [CRT5] & 14.29 & 14.29 & 6.00 \\
\hline [CRT4] & 7.15 & 7.15 & 3.00 \\
\hline [ all lower] & 0.00 & 0.00 & 0.00 \\
\hline
\end{tabular}

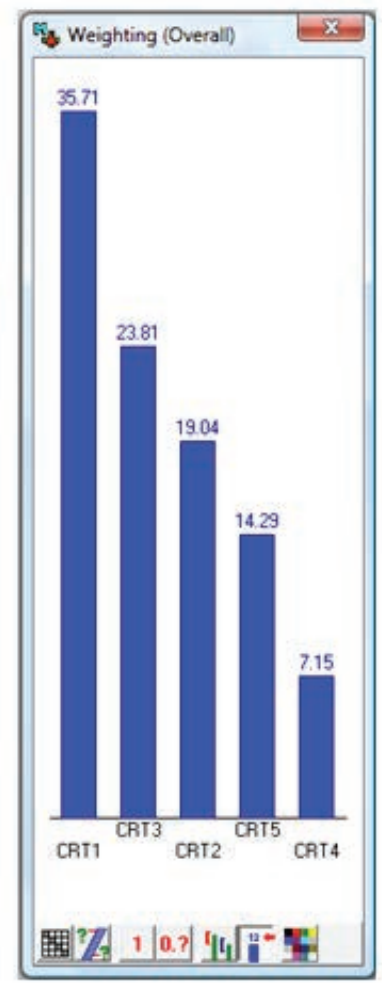

Figure 4. Criteria weights 


\subsubsection{Measuring bank branch potential attractiveness}

Information on bank branches had to be requested before measuring bank branch potential attractiveness. In their reply to our request, information regarding four bank branches was randomly and anonymously provided by Caixa Geral de Depósitos (CGD) (one of the largest banks that operate in Portugal). Despite the low number of branches under evaluation, the limited time period of the information (i.e. one month) and the fact that the selection of the branches resulted from a CGD's administrative decision, it should be emphasized that the information given was extremely useful, not only to test the framework in a real context but also to increase the interest and the discussion among the decision makers.

Before evaluating the overall potential attractiveness, we first calculated partial attractiveness values for each bank branch. This was accomplished based on the descriptors and on the cardinal value functions previously obtained for each one of the criteria included in the framework (cf. Figure 3). Table 2 shows the partial attractiveness performances of the four bank branches under evaluation (called Alphas).

Based on the results presented in Table 2, we should clarify that Good and Neutral are two fictitious bank branches that have been included in the framework to facilitate the decision makers' cognitive comparisons. Good represents a branch that performs at a good level for all criteria involved, while the Neutral represents a branch that performs at a neutral level for all criteria and, therefore, is not considered attractive or unattractive. At this stage, it became possible to understand and compare the performance of the branches in accordance to each of the criteria. For example, Alpha 1 reveals the best performance levels of $\mathrm{CRT}_{1}$, $\mathrm{CRT}_{2}, \mathrm{CRT}_{4}$ and $\mathrm{CRT}_{5}$, but it also reveals the worst performance level of the criterion $\mathrm{CRT}_{3}$, and this will influence its overall assessment. However, its performance on $\mathrm{CRT}_{3}$ seems to be important from a constructive perspective, not only because it will enable decision makers or other actors involved to better understand the branch's performance but also because it will allow them to propose and, if possible, implement adjustment/improvement suggestions. Once this stage was completed, the branches' local ratings were aggregated based on the additive model presented in (5). Table 3 shows the branches' partial and overall values.

Once the overall performance scores for the four bank branches were calculated their ranking was revealed. From the values presented (cf. Table 3), Alpha 3 offered the best performance with an overall score of 113.63, while Alpha 4 revealed to be the worst branch with an overall score of 2.71 . However, as previously mentioned (section 2.1 .2 ), rankings are not the major goal of the proposed framework. Instead, the emphasis should be put on a constructive discussion on adjustments/improvements that should emerge from the results.

Table 2. Levels and Values of partial attractiveness revealed by the evaluated branches

\begin{tabular}{lllllllllll}
\hline & $\mathrm{CRT}_{1}$ & & $\mathrm{CRT}_{2}$ & & $\mathrm{CRT}_{3}$ & & $\mathrm{CRT}_{4}$ & \multicolumn{3}{c}{$\mathrm{CRT}_{5}$} \\
\hline Alpha 1 & $\mathrm{L}_{1}$ & 200 & $\mathrm{~L}_{1}$ & 125 & $\mathrm{~L}_{11}$ & -83.33 & $\mathrm{~L}_{1}$ & 216.67 & $\mathrm{~L}_{1}$ & 140 \\
Alpha 2 & $\mathrm{L}_{1}$ & 200 & $\mathrm{~L}_{7}$ & -87.5 & $\mathrm{~L}_{7}$ & 33.33 & $\mathrm{~L}_{4}$ & -16.67 & $\mathrm{~L}_{7}$ & -20 \\
Alpha 3 & $\mathrm{L}_{1}$ & 200 & $\mathrm{~L}_{1}$ & 125 & $\mathrm{~L}_{7}$ & 33.33 & $\mathrm{~L}_{5}$ & -133.33 & $\mathrm{~L}_{1}$ & 140 \\
Alpha 4 & $\mathrm{L}_{3}$ & 0 & $\mathrm{~L}_{6}$ & -50 & $\mathrm{~L}_{7}$ & 33.33 & $\mathrm{~L}_{2}$ & 100 & $\mathrm{~L}_{7}$ & -20 \\
Good & $\mathrm{L}_{2}$ & 100 & $\mathrm{~L}_{2}$ & 100 & $\mathrm{~L}_{5}$ & 100 & $\mathrm{~L}_{2}$ & 100 & $\mathrm{~L}_{3}$ & 100 \\
Neutral & $\mathrm{L}_{3}$ & 0 & $\mathrm{~L}_{4}$ & 0 & $\mathrm{~L}_{8}$ & 0 & $\mathrm{~L}_{3}$ & 0 & $\mathrm{~L}_{6}$ & 0 \\
\hline
\end{tabular}


Table 3. Partial values and overall attractiveness revealed by the four branches

\begin{tabular}{lllllll}
\hline & Global & $\mathrm{CRT}_{1}$ & $\mathrm{CRT}_{2}$ & $\mathrm{CRT}_{3}$ & $\mathrm{CRT}_{4}$ & $\mathrm{CRT}_{5}$ \\
\hline Alpha 1 & 110.88 & 200 & 125 & -83.33 & 216.67 & 140 \\
Alpha 2 & 58.65 & 200 & -87.5 & 33.33 & -16.67 & -20 \\
Alpha 3 & 113.63 & 200 & 125 & 33.33 & -133.33 & 140 \\
Alpha 4 & 2.71 & 0 & -50 & 33.33 & 100 & -20 \\
Good & 100 & 100 & 100 & 100 & 100 & 100 \\
Neutral & 0 & 0 & 0 & 0 & 0 & 0 \\
\hline Weights & & 0.3571 & 0.1904 & 0.2381 & 0.0715 & 0.1429 \\
\hline
\end{tabular}

\subsubsection{Analysing results}

The multiple criteria framework developed in this paper allowed bank decision makers to: (i) provide a ranking and discrimination among the bank branches studied according to a model that was constructed based on their own experiences and semantic judgements; (ii) compare the relative positions of the branches based on cognitive comparisons with two cognitive references (Good and Neutral); (iii) facilitate additional discussions regarding the results, that allowed for an increase in transparency and, accordingly, of their knowledge on the decision making problem; (iv) present and discuss well focused suggested improvements based on the lower performance achieved by the branches in some of the criteria; and (v) demonstrate the practical applicability of the integrated application of cognitive maps and the MACBETH approach in a bank branch potential attractiveness evaluation context.

Based on the literature (e.g. Bana e Costa and Chagas, 2004; Ferreira et al., 2011a), the evaluation phase may be considered completed once a final ranking is obtained, discussed and approved by the decision makers. However, additional analyses were conducted (e.g. sensitivity and robustness analysis). Figure 5 exemplifies the sensitivity analysis carried out for $\mathrm{CRT}_{1}$.

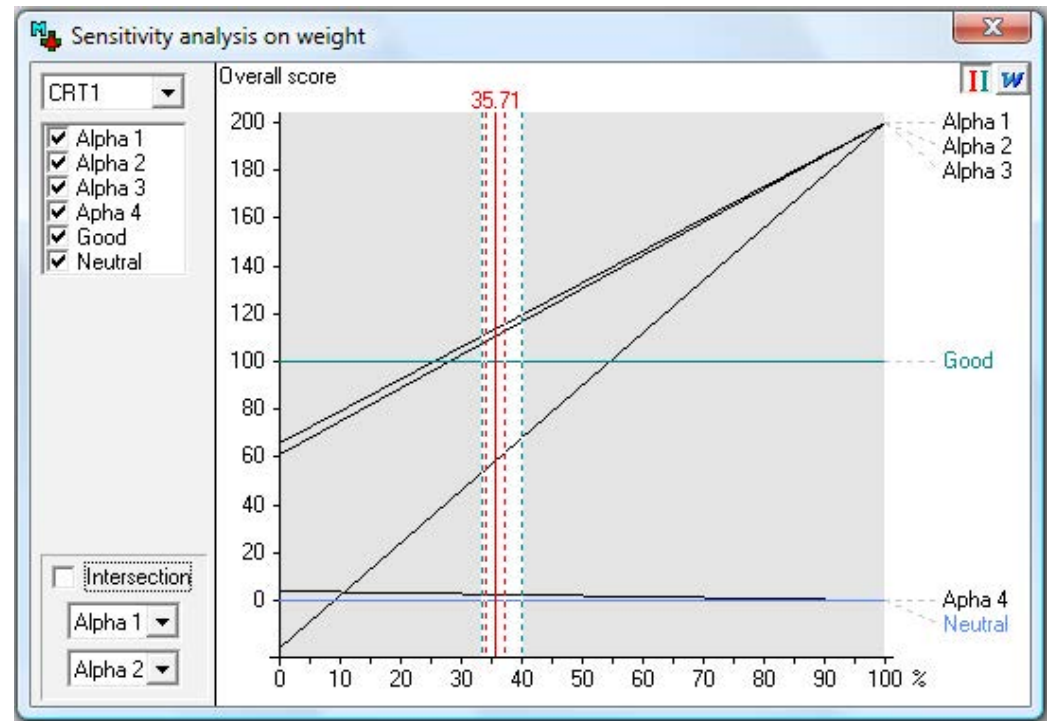

Figure 5. Sensitive analysis on $\mathrm{CRT}_{1}$ 
As shown in Figure 5, the weight attributed to $\mathrm{CRT}_{1}$ is 35.71 and the sensitivity analysis developed in our study for this criterion allows us to conclude that the model is relatively strong because the criterion's weight can vary significantly without violating the alphas' final ranking and, consequently, the decision makers' value judgements. At this stage, it should be underlined that these additional analyses were carried out not only to validate the achieved results and determine the stability of the proposed framework but also to promote additional discussion among decision makers and determine the basis for recommendations.

\subsection{The recommendation phase of the study}

Although the present multiple criteria framework allowed us to achieve encouraging results, namely based on the receptiveness and satisfaction expressed by decision makers, the major reason for success is the process itself. This is not an outcome-oriented study but a process-oriented application where a nonprescriptive position has been assumed since the beginning. For this reason, despite of the versatility and flexibility offered by the technical procedures, the present framework should be seen as a learning mechanism and not as an end in itself or a tool to prescribe optimal solutions. Thus, the achieved results are aimed at encouraging discussion among decision makers and promoting a better understanding of the criteria associated with bank branch potential attractiveness assessment. Because results are strongly dependent on the context of the analysis and on the actors involved, it is highly recommended that any generalization to other contexts or group of actors should be carefully analyzed. Obviously, it may be argued that this may be one of the framework's weaknesses. However, the integrated evaluation methodology proposed in this study also offers adjustment possibilities (e.g. adjusting the weights in order to capture different stra- tegic priorities and orientations). From this point of view, it seems also important to perform extra sensitivity and robustness analyses after any adjustment.

\section{DISCUSSION AND CONCLUDING REMARKS}

As a consequence of the recent financial crisis, banks have encountered increasing competitive challenges worldwide. A key aspect is, therefore, to understand the implications of increased competition for retail banking, where it is imperative that banking institutions "place more emphasis on improving internal operational performance" (Wu, 2012: 303). On this basis, a multiple criteria framework has been developed and presented in order to evaluate bank branch potential attractiveness. The interpretation of "potential attractiveness" was clarified by rating external variables that fall outside (totally or partially) the banks' sphere of control but create differentiation among existing bank branches by imposing strict constraints on their performance and influencing their profitability. Special emphasis may also be given to the fact that the multiple criteria framework resulted from professional bank decision makers perception of branch attractiveness and that it represents a process-oriented application. The main arguments in this paper are related to the fact that bank branch potential attractiveness evaluation is a multiple criteria problem, where decisions are not easily taken and are strongly dependent on several decision makers with different and (sometimes) conflicting values and perspectives. Therefore, searching for optimal solutions in this context seems to be an unrealistic possibility. Despite the remarkable progress that has taken place in the performance evaluation field (e.g. Kaplan and Norton, 1992 and 2000), it is widely recognized that issues remain that need further clarification, namely the process in which evaluation criteria are se- 
lected and the way that trade-offs among those criteria are explicitly assessed (for further discussion, see Zopounidis and Doumpos, 2002; Brauers and Zavadskas, 2011). In our study, we use cognitive maps to support criteria selection and we apply the MACBETH approach to obtain the criteria relative weights. The integrated use of both methodologies allowed us to support the development of a multidimensional performance evaluation system that deals with the bank branch potential attractiveness problem. To the best of our knowledge this has not been done before in the literature, and banks can significantly benefit from the application of performance measurement tools in terms of bank branch potential attractiveness and facilities management, namely because of the intangible nature of the criteria involved. Above all, our study provides evidence that the assessment of bank branch attractiveness through the integrated use of cognitive mapping and the MACBETH approach can ultimately have a strategic planning purpose, assisting bank managers to obtain important information to both support decisions regarding the scaling up of operations or, alternatively, the closing of branches. Following this, and along with possibly other applications, our framework may be useful to: (i) assist decision makers in better setting goals for the existing bank branches according to their local features; (ii) monitor the branches' progress over time; and (iii) possibly identify actions that will improve bank branch attractiveness while considering local competitive and demographic factors (for a broader discussion, see also Zhang et al., 2011). As an example, alternative branch locations may be compared to assess advantages and/or disadvantages of different locations. Although not an objective of this study, our framework could also serve as a starting point to select high potential service segments within the branch's current trade area, or be applied as a preliminary basis for the development of sourcing strategies in fa- cilities management (Ventovuori, 2006; Farahani et al., 2012) and/or decisions supporting branches' closure. From a conceptual point of view, the integrated approach presented in this study provides a mechanism to incorporate the decision makers' knowledge and preferences and enables them to coordinate their decision making to achieve better solutions. As quoted by Zavadskas and Turskis (2011: 398), "most importantly perhaps was the finding that decision analysis can be useful to help multiple stakeholders understand what they agree and disagree about, focus on the things that they disagree about and explore options that are better for everyone involved".

The multiple criteria analysis framework presented takes into account quantitative and qualitative criteria and reduces the problem of omitted criteria (by using cognitive maps). It also increases transparency in the way that criteria are selected and the way trade-offs among criteria are determined by using cognitive maps and the MACBETH technique, respectively. In line with what has been presented, the results of our framework are very encouraging. Nonetheless, its outcomes should be considered with proper reservation due to the strong dependence on the context of analysis and the actors involved. Furthermore, it is important to remember that the procedure we propose is inherently subjective in the choice of measures and in the weighting of these measures. While this may be seen as an important limitation, the proponents of the MCDA approach argue that all decision making is subjective and that the major value of this approach is to make such subjectivity explicit and integrate it in a transparent way with objective data ( $c f$. Santos et al., 2002). As such, future research and more case studies are strongly encouraged. In particular, it seems important to: (1) conduct a panel study with a different set of managers in the same industry to determine the robustness of our results; (2) conduct a panel study within a different industry and/or a different 
country to increase the generalizability; (3) create a survey based on panel studies in order to receive feedback from more than just a few managers to increase the reliability of the results; and (4) conduct a methodological study to compare the results obtained from the application of different methods in the context under analysis. In addition to this research, we also need to assess the consequences of the recent global crisis on the process of performance assessment of banking institutions. Eventual improvements and/or updates will strengthen the potential of the approach proposed in this paper.

\section{ACKNOWLEDGEMENTS}

This paper was developed under Post-Doctoral research undertaken at the Department of Finance, Insurance and Real Estate of the Fogelman College of Business and Economics, University of Memphis, USA. The first author is grateful to Calouste Gulbenkian Foundation for the financial support [Research Fellowship 21-101425-B].

\section{REFERENCES}

Ackermann, F. and Eden, C. (2001) SODA - Journey making and mapping in practice. In: Rosenhead, J. and Mingers, J. (eds.), Rational analysis for a problematic world revisited: Problem structuring methods for complexity, uncertainty and conflict (second edition), John Wiley \& Sons, Chichester, pp. 43-60.

Akhigbe, A. and McNulty, J. (2011) Bank monitoring, profit efficiency and the commercial lending business model, Journal of Economics and Business, 63(6), pp. 531-551.

http://dx.doi.org/10.1016/j.jeconbus.2011.07.001

Ananda, J. and Herath, G. (2009) A critical review of multi-criteria decision making methods with special reference to forest management and planning, Ecological Economics, 68(10), pp. 2535-2548.

http://dx.doi.org/10.1016/j.ecolecon.2009.05.010
Avkiran, N. (1995) A multivariate model of integrated branch performance and potential focusing on personal banking. [Online] $\mathrm{PhD}$ thesis, Melbourne: Victoria University of Technology. Available at: http://vuir.vu.edu.au/15434/1/ Avkiran_1995_compressed.pdf [accessed 11 February 2012]

Bana e Costa, C. and Chagas, M. (2004) A career choice problem: An example of how to use MACBETH to build a quantitative value model based on qualitative value judgements, European Journal of Operational Research, 153(2), pp. 323-331. http://dx.doi.org/10.1016/S03772217(03)00155-3

Bana e Costa, C. and Vansnick, J. (1994) MACBETH: An interactive path towards the construction of cardinal value functions, International Transactions in Operational Research, 1(4), pp. 489-500. http://dx.doi.org/10.1016/0969-6016(94)90010-8

Bana e Costa, C. and Vansnick, J. (1999) Preference relations and MCDM. In: Gál, T., Stewart, T. and Hanne, T. (eds.), Multiple criteria decision making: Advances in MCDM models, algorithms, theory, and applications, Kluwer Academic Publishers, Massachusetts, pp. 4-23.

Bana e Costa, C., De Corte, J. and Vansnick, J. (2005) On the mathematical foundations of MACBETH. In: Figueira, J., Greco, S. and Ehrgott, M. (eds.), Multiple criteria decision analysis: The state of the art surveys, Springer, New York, pp. 409-442.

Bana e Costa, C., Lourenço, J., Chagas, M. and Bana e Costa, J. (2008) Development of reusable bid evaluation models for the Portuguese electric transmission company, Decision Analysis, 5(1), pp. 22-42.

http://dx.doi.org/10.1287/deca.1080.0104

Bana e Costa, C., De Corte, J. and Vansnick, J. (2012) MACBETH, International Journal of Information Technology and Decision Making, 11(2), pp. 359-387.

Barros, C., Ferreira, C. and Williams, J. (2007) Analysing the determinants of performance of best and worst European banks: A mixed logit approach, Journal of Banking and Finance, 31(7), pp. 2189-2203.

http://dx.doi.org/10.1016/j.jbankfin.2006.11.010

Belton, V. and Stewart, T. (2002) Multiple criteria decision analysis: An integrated approach, Kluwer Academic Publishers, Dordrecht. 
Beltratti, A. and Stulz, R. (2012) The credit crisis around the globe: Why did some banks perform better?, Journal of Financial Economics, 105(1), pp. 1-17.

http://dx.doi.org/10.1016/j.jfineco.2011.12.005

Bergendahl, G. and Lindblom, T. (2008) Evaluating the performance of Swedish savings banks according to service efficiency, European Journal of Operational Research, 185(3), pp. 1663-1673. http://dx.doi.org/10.1016/j.ejor.2006.08.027

Bontis, N., Booker, L. and Serenko, A. (2007) The mediating effect of organizational reputation on customer loyalty and service recommendation in the banking industry, Management Decision, 45(9), pp. 1426-1445. http://dx.doi.org/10.1108/00251740710828681

Boufounou, P. (1995) Evaluating bank branch location and performance: A case study, European Journal of Operational Research, 87(2), pp. 389-402.

http://dx.doi.org/10.1016/0377-2217(92)00080-5

Brauers, W. K. M. and Zavadskas, E. K. (2011) Multimoora optimization used to decide on a bank loan to buy property, Technological and Economic Development of Economy, 17(1), pp. $174-188$.

http://dx.doi.org/10.3846/13928619.2011.560632

Carmeli, A. (2004) Assessing core intangible resources, European Management Journal, 22(1), pp. 110-122.

http://dx.doi.org/10.1016/j.emj.2003.11.010

Cossette, P. and Audet, M. (2003) Qu'est qu'une carte cognitive? In: Cossette, P. (ed.), Cartes cognitives et organizations, [Online] Les Éditions de L'ADREG. Available at: http://asso. nordnet.fr/adreg/Adreg_05.pdf, pp. 31-60 [accessed 11 February 2012]

D'Amato, M. (2010) A location value response surface model for mass appraising: An "iterative" location adjustment factor in Bari, Italy, International Journal of Strategic Property Management, 14(3), pp. 231-244.

http://dx.doi.org/10.3846/ijspm.2010.17

Davies, M. (1996) Image problems with financial services: some considerations for improvement, Management Decision, 34(2), pp. 64-71. http://dx.doi.org/10.1108/00251749610110355

Davis, S. and Albright, T. (2004) An investigation of the effect of balanced scorecard implementation on financial performance, Management Accounting Research, 15(2), pp. 135-153. http://dx.doi.org/10.1016/j.mar.2003.11.001

Dyer, R. and Forman, E. (1992) Group decision support with the analytic hierarchy process, Decision Support Systems, 8(2), 99-124.

http://dx.doi.org/10.1016/0167-9236(92)90003-8

Eden, C. (2004) Analyzing cognitive maps to help structure issues or problems, European Journal of Operational Research, 159(3), pp. 673-686. http://dx.doi.org/10.1016/S0377-2217(03)00431-4

Eden, C. and Ackermann, F. (2001a) Group decision and negotiation in strategy making, Group Decision and Negotiation, 10(2), pp. 119-140. http://dx.doi.org/10.1023/A:1008710816126

Eden, C. and Ackermann, F. (2001b) SODA - The principles. In: Rosenhead, J. and Mingers, J. (eds.), Rational analysis for a problematic world revisited: Problem structuring methods for complexity, uncertainty and conflict (second edition), John Wiley \& Sons, Chichester, pp. 21-41.

Eden, C. and Ackermann, F. (2004) Cognitive mapping expert views for policy analysis in the public sector, European Journal of Operational Research, 152(3), pp. 615-630. http://dx.doi. org/10.1016/S0377-2217(03)00061-4

Farahani, R., Asgari, N., Heidari, N., Hosseininia, M. and Goh, M. (2012) Covering problems in facility location: A review, Computers \& Industrial Engineering, 62(1), pp. 368-407. http://dx.doi.org/10.1016/j.cie.2011.08.020

Ferreira, F., Santos, S. and Rodrigues, P. (2011a) Adding value to bank branch performance evaluation using cognitive maps and MCDA: A case study, Journal of the Operational Research Society, 62(7), pp. 1320-1333. http://dx.doi.org/10.1057/jors.2010.111

Ferreira, F., Spahr, R. and Pereira, J. (2011b) New banking trends, MCDA and financial decisions: Insights and a framework for retail banking, Banks and Bank Systems, 6(2), pp. 23-35.

Frei, F. and Harker, P. T. (1999) Measuring the efficiency of service delivery processes: An application to retail banking, Journal of Service Research, 1(4), pp. 300-312. http://dx.doi.org/10.1177/109467059914002

Frei, F., Kalakota, R., Leone, A. and Marx, L. (1999) Process variation as a determinant of bank performance: Evidence from the retail banking study, Management Science, 45(9), pp. 1210 1220. http://dx.doi.org/10.1287/mnsc.45.9.1210 
Hartman, T., Storbeck, J. and Byrnes, P. (2001) Allocative efficiency in branch banking, European Journal of Operational Research, 134(2), pp. 232-242. http://dx.doi.org/10.1016/S03772217(00)00257-5

Hirtle, B. (2007) The impact of network size on bank branch performance, Journal of Banking and Finance, 31(12), pp. 3782-3805.

http://dx.doi.org/10.1016/j.jbankfin.2007.01.020

Ittner, C., Larcker, D. and Meyer, M. (1997) Performance, compensation and the balanced scorecard, The University of Pennsylvania, Pennsylvania.

Junior, H. (2008) Multicriteria approach to data envelopment analysis, Pesquisa Operacional, 28(2), pp. 231-242. http://dx.doi.org/10.1590/ S0101-74382008000200004

Kaplan, R. and Norton, D. (1992) The balanced scorecard: Measures that drive performance, Harvard Business Review, 70(1), pp. 71-79.

Kaplan, R. and Norton, D. (2000) Having trouble with your strategy? Then map it, Harvard Business Review, 78(5), pp. 167-176.

Kauko, T. (2007) An analysis of housing location attributes in the inner city of Budapest, Hungary, using expert judgements, International Journal of Strategic Property Management, 11(4), pp. 209-225. http://dx.doi.org/10.1080/1 648715X.2007.9637570

Kauko, T. (2010) Value stability in local real estate markets, International Journal of Strategic Property Management, 14(3), pp. 191-199. http://dx.doi.org/10.3846/ijspm.2010.14

Kaya, T. and Kahraman, C. (2011) A fuzzy approach to e-banking website quality assessment based on an integrated AHP-ELECTRE method, Technological and Economic Development of Economy, 17(2), pp. 313-334. http://dx.doi.org /10.3846/20294913.2011.583727

Keeney, R. (1992) Value-focused thinking: A path to creative decisionmaking, Harvard, University Press Harvard.

Kowalski, T. and Shachmurove, Y. (2011) The financial crisis: What is there to learn?, Global Finance Journal, 22(3), pp. 238-247. http://dx.doi.org/10.1016/j.gfj.2011.10.014

Manandhar, R. and Tang, J. (2002) The evaluation of bank branch performance using data envelopment analysis: A framework, Journal of
High Technology Management Research, 13(1), pp. 1-17. http://dx.doi.org/10.1016/S10478310(01)00045-1

Paradi, J. and Schaffnit, C. (2004) Commercial branch performance evaluation and results communication in a Canadian bank: A DEA application, European Journal of Operational Research, 156(3), pp. 719-735. http://dx.doi. org/10.1016/S0377-2217(03)00108-5

Parkan, C. and Wu, M. (1999) Measurement of the performance of an investment bank using the operational competitiveness rating procedure, Omega: The International Journal of Management Sciences, 27(2), pp. 201-217. http://dx.doi. org/10.1016/S0305-0483(98)00041-3

Puri, M., Rocholl, J. and Steffen, S. (2011) Global retail lending in the aftermath of the US financial crisis: Distinguishing between supply and demand effects, Journal of Financial Economics, 100(3), pp. 556-578. http://dx.doi.org/10.1016/j.jfineco.2010.12.001

Roy, B. and Vanderpooten, D. (1997) An overview on "the European school of MCDA: Emergence, basic features and current works", European Journal of Operational Research, 99(1), pp. 26-27.

http://dx.doi.org/10.1016/S0377-2217(96)00379-7

Santos, S., Belton, V. and Howick, S. (2002) Adding value to performance measurement by using systems dynamics and multicriteria analysis, International Journal of Operations \& Production Management, 22(11), pp. 1246-1272. http://dx.doi.org/10.1108/01443570210450284

Santos, S., Belton, V. and Howick, S. (2008) Enhanced performance measuring using OR: A case study, Journal of the Operational Research Society, 59(6), pp. 762-775.

http://dx.doi.org/10.1057/palgrave.jors.2602397

Serna, R. (2005) Where are the bank branches in my community? An analysis of branch distribution in low-income neighborhoods. [Online] California Reinvestment Coalition Report. Available at: http://www.centralvalleybusinesstimes.com/ links/CRC_bank_branch_analysis.pdf [accessed 11 February 2012]

Spahr, R. and Sunderman, M. (2012) The U.S. housing finance debacle: Reform of Fannie Mae and Freddie Mac to control credit and interest rate risk, Working Paper and under review at the Journal of Real Estate Research. 
Suwignjo, P., Bititci, U. and Carrie, A. (2000) Quantitative models for performance measurement system, International Journal of Production Economics, 64(1/3), pp. 231-241. http://dx.doi. org/10.1016/S0925-5273(99)00061-4

Ventovuori, T. (2006) Elements of sourcing strategies in FM services: A multiple case study, International Journal of Strategic Property Management, 10(4), pp. 249-267. http://dx.doi. org/10.1080/1648715X.2006.9637556

Weber, M. and Borcherding, K. (1993) Behavioral influences on weight judgments in multiattribute decision making, European Journal of Operational Research, 67(1), pp.1-12. http://dx.doi.org/10.1016/0377-2217(93)90318-H

Wu, H. (2012) Constructing a strategy map for banking institutions with key performance indicators of the balanced scorecard, Evaluation and Program Planning, 35(3), pp. 303-320. http:// dx.doi.org/10.1016/j.evalprogplan.2011.11.009

Xiao-yan, Z., Yan-lei, Q. and Peilong, S. (2012) Review of the international financial trends in post financial crisis era, Procedia Engineering, 15, pp. 4795-4799.

http://dx.doi.org/10.1016/j.proeng.2011.08.896

Yeager, T. (2011) Causes, consequences and cures of the subprime financial crisis, Journal of Economics and Business, 63(5), pp. 345-348. http://dx.doi.org/10.1016/j.jeconbus.2011.05.004
Zavadskas, E. K. and Turskis, Z. (2011) Multiple criteria decision making (MCDM) methods in economics: An overview, Technological and Economic Development of Economy, 17(2), pp. 397-427. http://dx.doi.org/10.3846/2029491 3.2011 .593291

Zhang, X., Tan, Y., Shen, L. and Wu, Y. (2011) An alternative approach of competitiveness evaluation for real estate developers, International Journal of Strategic Property Management, 15(1), pp. 10-25. http://dx.doi.org/10.3846/164 8715X.2011.565911

Zhao, L., Garner, B. and Parolin, B. (2004) Branch bank closures in Sydney: A geographical perspective and analysis. In: Proceedings of the 12 th international conference on geoinformatics, Sweden, pp. 541-548.

Zopounidis, C. (1999) Multicriteria decision aid in financial management, European Journal of Operational Research, 119(2), pp. 404-415. http:// dx.doi.org/10.1016/S0377-2217(99)00142-3

Zopounidis, C. and Doumpos, M. (2002) Multicriteria classification and sorting methods: A literature review, European Journal of Operational Research, 138(2), pp. 229-246. http://dx.doi. org/10.1016/S0377-2217(01)00243-0

Zopounidis, C. and Doumpos, M. (2003) Multi-criteria decision aid in financial decision making: Methodologies and literature review, Journal of Multi-Criteria Decision Analysis, 11(4/5), pp. 167-186. http://dx.doi.org/10.1002/mcda.333 